\title{
Rescue Thrombectomy for Early Hepatic Artery Thrombosis Using Stent Retriever in a Child Post Combined Deceased Donor Liver and Renal Transplant
}

\author{
${ }^{1}$ Division of Interventional Radiology, Department of Radiology, \\ Kerala Institute of Medical Sciences, Trivandrum, Kerala, India \\ ${ }^{2}$ Department of Radiology, Kerala Institute of Medical Sciences, \\ Trivandrum, Kerala, India \\ ${ }^{3}$ Department of Hepatobiliary, Pancreatic and Liver Transplant \\ Surgery, Kerala Institute of Medical Sciences, Trivandrum, Kerala, \\ India \\ J Clin Interv Radiol ISVIR 2021;5:193-195.
}

Manish Kumar Yadav ${ }^{1}$ Madhavan Unni ${ }^{2}$ Shabeer Ali T. U. ${ }^{3} \quad$ Shiraz Ahmed Rather ${ }^{3}$ Venugopal B. ${ }^{3}$

\author{
Address for correspondence Manish Kumar Yadav, MBBS, DMRD, \\ DNB, FNVIR, EBIR, 12A, Ivory, SFS Cyberpalms, Bypass Road, \\ Near MGM School, Trivandrum 695583, Kerala, India \\ (e-mail:drmanishyadav@yahoo.co.in).
}

\begin{abstract}
Keywords

- combined deceased donor liver and renal transplant

- hepatic artery thrombosis

- stent retriever

- mechanical thrombectomy

We report this case of a 5-year-old child post combined liver and renal transplant for primary hyperoxaluria. Patient developed hepatic artery thrombosis on day 3 posttransplant that was managed by reexploration and reanastomosis of the hepatic artery. On day 4, the patient again developed hepatic artery thrombosis that failed to revascularize by surgical exploration and reanastomosis. Tissue plasminogen activator was injected into the hepatic artery intraoperatively to lyse any clot; however, no revascularization could be achieved. Subsequently, catheter angiogram confirmed no flow in the hepatic artery. A4 $\times 22 \mathrm{~mm}$ revive stent retriever was deployed across the site of occlusion and retrieved after 5 minutes of indwell time. Two such passes were made and complete recanalization of the hepatic artery was achieved. The hepatic artery remained patent as confirmed on serial Doppler images post intervention.
\end{abstract}

\section{Dear Editor,}

We report a case of acute hepatic artery thrombosis and its endovascular management in a 5-year-old male child who underwent combined deceased donor liver and renal transplant for primary hyperoxaluria type I with chronic kidney failure. Immediate postprocedure both renal and liver graft functions were stable. On postoperative day 3, routine liver Doppler examination revealed absent hepatic artery signals that were also confirmed by computed tomography angiogram ( - Fig. 1). Although there was a rise in total bilirubin by $0.5 \mathrm{mg} / \mathrm{dL}$, the aspartate aminotransferase (AST; $210 \mathrm{mg} / \mathrm{dL}$ ), alanine aminotransferase (ALT; $121 \mathrm{mg} / \mathrm{dL}$ ), and gamma glutamine transferase (GGT; $160 \mathrm{mg} / \mathrm{dL}$ ) remained stable. Patient underwent exploratory laparotomy and dismantling of the hepatic arterial anastomosis followed by reanastomosis of hepatic artery to avoid any future biliary complications. The patient was started on continuous infusion of intravenous heparin titrated to partial thromboplastin time done every 6 hours to maintain it at two to two and half times the control value. Liver Doppler 12 hours after reanastomosis confirmed good hepatic arterial signal from the hepatic allograft.

The routine liver Doppler 24 hours after reanastomosis showed absence of hepatic artery flow signal. The liver enzymes showed mild elevation in the values: total bilirubin, $1.3 \mathrm{mg} / \mathrm{dL}$; AST, $271 \mathrm{mg} / \mathrm{dL}$; ALT, $276 \mathrm{mg} / \mathrm{dL}$; and GGT, $190 \mathrm{mg} / \mathrm{dL}$. Patient was taken up for a third laparotomy. On dismantling the anastomosis, no back-bleeding was noted from the donor side of the hepatic artery stump; tissue plasminogen activator was injected directly into the arterial stump at a dose of $0.06 \mathrm{mg} / \mathrm{kg}$. Post injection no back-bleeding was noted even after full target published online April 29, 2021
DOI https://doi.org/

$10.1055 / \mathrm{s}-0041-1728984$ ISSN 2457-0214 (c) 2021. Indian Society of Vascular and Interventional Radiology. This is an open access article published by Thieme under the terms of the Creative Commons Attribution-NonDerivative-NonCommercial-License, permitting copying and reproduction so long as the original work is given appropriate credit. Contents may not be used for commercial purposes, or adapted, remixed, transformed or built upon. (https://creativecommons.org/licenses/by-nc-nd/4.0/). Thieme Medical and Scientific Publishers Pvt. Ltd. A-12, 2nd Floor, Sector 2, Noida-201301 UP, India 


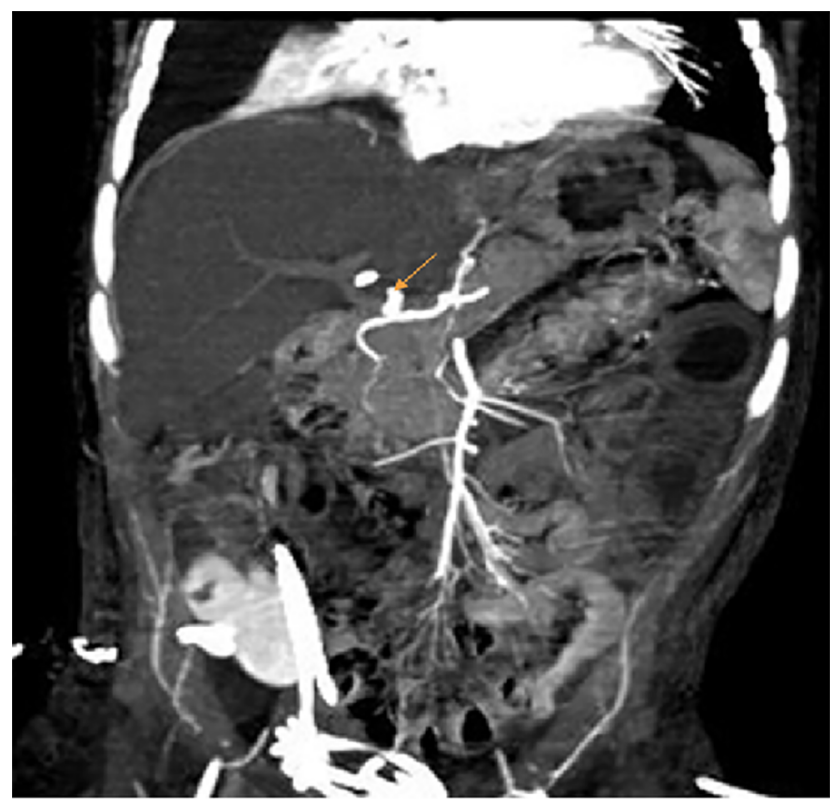

Fig. 1 Computed tomography angiogram of coronal maximum intensity projection showing hepatic artery stump (orange arrow). No contrast filling of the hepatic artery is noted beyond the anastomotic site.

dose administration. Since all surgical and assisted attempts to achieve good flow in hepatic artery to the allograft liver were unsuccessful, it was decided to proceed with endovascular approach to achieve revascularization. The hepatic artery anastomosis was redone and the abdomen was closed.

The available conventional endovascular options were systemic thrombolysis, intraarterial thrombolytic therapy, mechanical thrombectomy, or retransplantation. Systemic thrombolysis and intraarterial thrombolytic therapy both were not considered in view of recent major surgery and patient was in receipt of thrombolytic therapy in therapeutic doses. Retransplantation was a distant option due to limited availability of deceased donors in this part of the world.

In view of limited revascularization options, it was decided to proceed with mechanical thrombectomy using a stent retrieval device. The celiac artery was engaged with a 4 French cobra catheter (Cordis Corporation, Cordis Cashel, Co Tipperary, Ireland). Initial digital subtraction angiogram showed complete occlusion of hepatic artery stump ( - Fig. 2). The anastomotic occlusion was crossed with a combination of synchro 2, 0.014 guidewire (Stryker Neurovascular, Levallois-Perret, Paris, France) and Prowler select Plus Microcatheter (Codman, Johnson \& Johnson Medical Limited, Wokingham RG40 3EW, United Kingdom). After confirming the position of the microcatheter in distal patent hepatic arterial branch, a $4 \times 22 \mathrm{~mm}$ Revive SE stent retriever device (Codman \& Shurtleff, Inc., Massachusetts, United States) ( - Fig. 3) was deployed across the occluded segment. After a dwell time of 5 minutes, the device was retrieved. Two such passes were made following which a check angiogram showed complete recanalization of the hepatic artery with good filling of the peripheral branches ( $\neg$ Fig. 4).

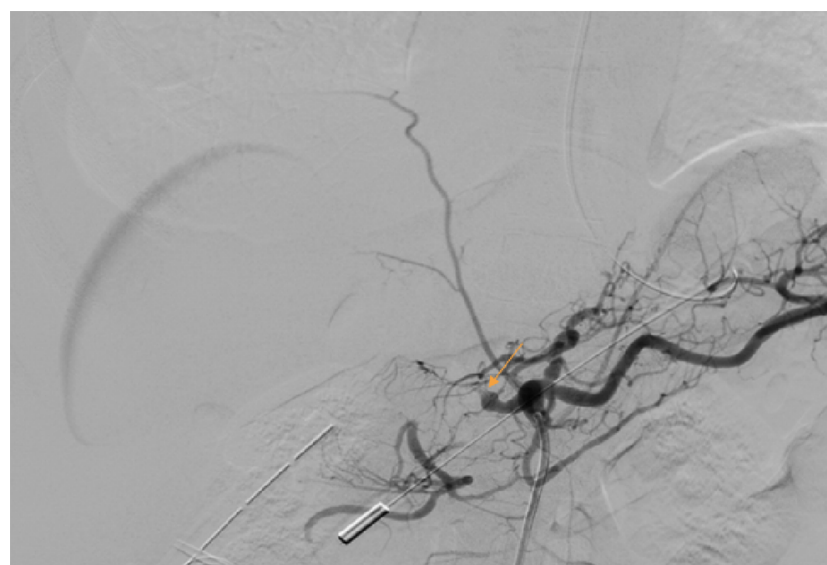

Fig. 2 Digital subtraction angiogram of celiac artery injection demonstrating the cutoff (orange arrow) at the anastomotic site with no filling of the intrahepatic branches of the hepatic artery.

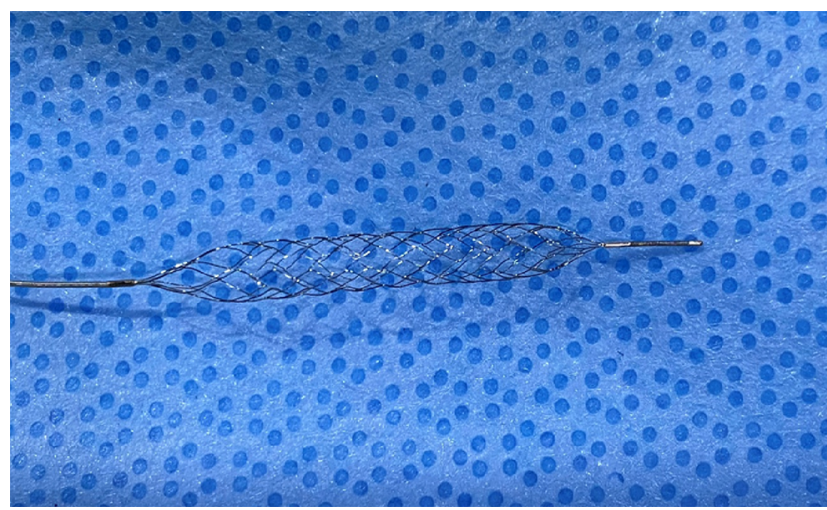

Fig. 3 Revive $4 \times 22 \mathrm{~mm}$ stent retriever mechanical thrombectomy device.

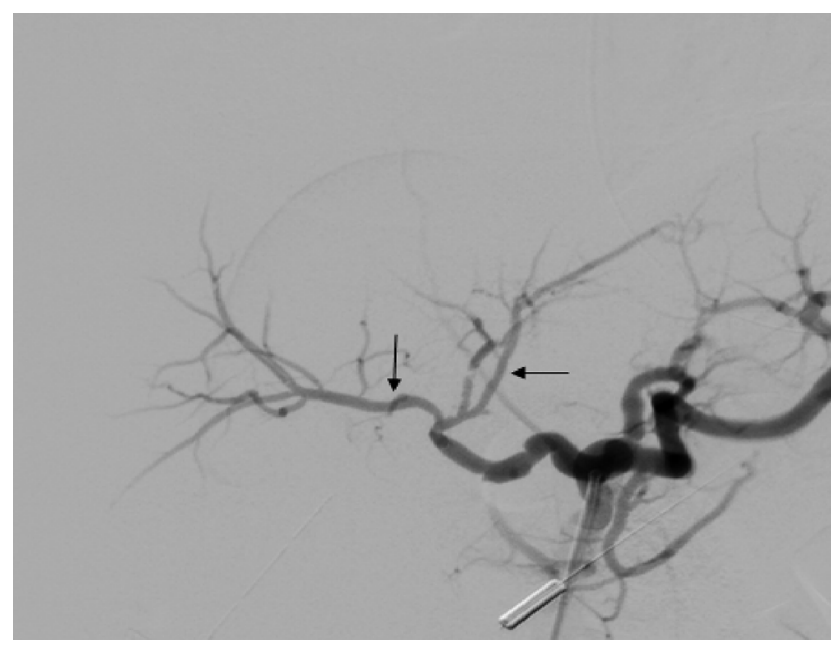

Fig. 4 Post-mechanical thrombectomy, digital subtraction angiogram showing good recanalization of the hepatic artery with filling of intrahepatic branches (black arrow).

Postprocedure hepatic allograft function continued to remain stable and liver enzymes showed declining trend: total bilirubin, $1 \mathrm{mg} / \mathrm{dL}$; AST, $205 \mathrm{mg} / \mathrm{dL}$; ALT, $137 \mathrm{mg} / \mathrm{dL}$; and GGT, 
$163 \mathrm{mg} / \mathrm{dL}$. Subsequent Doppler examinations showed good flow in the hepatic artery (-Fig. 5). Anticoagulation was achieved by intravenous heparin infusion for initial 48 hours with target partial thromboplastin time two to two and a half times control and was converted to low molecular weight heparin in therapeutic doses after 48 hours. Antiplatelet therapy could not be initiated due to platelet counts being persistently below $1 \mathrm{lakh} / \mathrm{cu} \mathrm{mm}$.

Patient developed febrile illness on post transplant day 21 along with gradual deterioration in the allograft hepatic function that was attributed to cytomegalovirus (CMV) infection detected on CMV polymerase chain reaction. Patient was started on therapeutic doses of ganciclovir. Percutaneous liver biopsy showed severe necrosis with inclusion bodies and no features of acute cellular rejection. Patient succumbed to fulminant CMV hepatitis on day 45 posttransplant. Serial Doppler studies till the demise of the child confirmed patency and good flow of the hepatic artery.

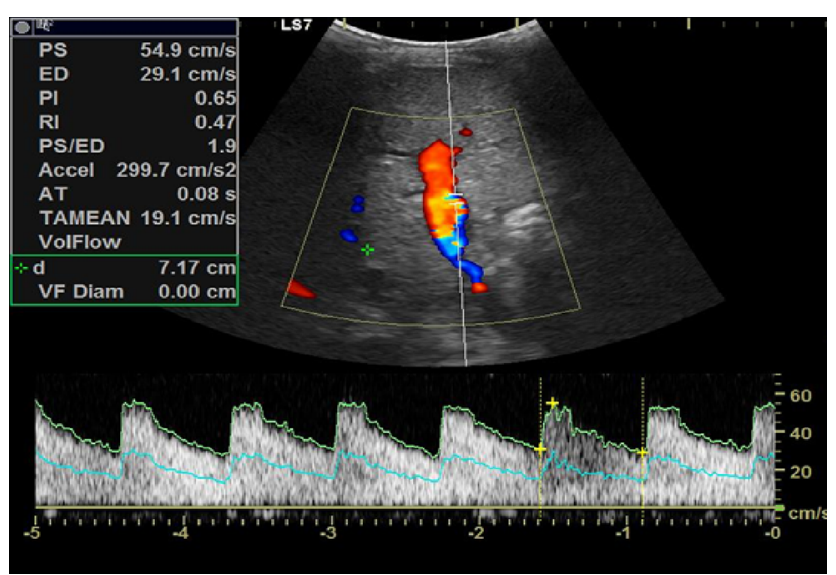

Fig. 5 Post-recanalization day 2, Doppler of intraparenchymal segment of hepatic artery showing strong arterial signal and normal waveform confirming patency of the hepatic artery.

\section{Discussion}

Hepatic artery thrombosis after a liver transplant is a dreaded complication due to associated high rates of graft loss, recipient mortality, and chronic complications such as multiple biliary strictures. Reported incidence of hepatic artery thrombosis varies from $2.5^{1}$ to $9 \%{ }^{2}$

Hepatic artery thrombosis is characterized into early (occurring within 30 days of transplant) or late (occurring after 30 days of transplant). ${ }^{3-5}$ In general, there are three lines of management for hepatic artery thrombosis; retransplantation, surgical revascularization, and endovascular revascularization. ${ }^{6}$ Early transplant hepatic artery thrombosis, occurring within 2 to 3 days is considered to be due to technical factors and are best managed by re-exploration and surgical revascularization as this facilitates correction of technical factors. Hepatic artery thrombosis after 3 days is difficult to manage surgically as adhesions are likely and may lead to further Graft pedicle injuries. These are the patients who benefit from endovascular revascularization as the potential risk of bleeding from raw wounds is relatively lower. Retransplantation is considered in cases that fail other revascularization techniques or deteriorating graft function in spite of successful revascularization.

The most common technique used in endovascular revascularization of posttransplant hepatic artery thrombosis is intraarterial thrombolysis. ${ }^{6}$ Various drugs used for thrombolysis include streptokinase, urokinase, and tissue plasminogen activator. Use of stent retrievers has become accepted mode of treatment in acute stroke and has become part of standard of care across the world. However, stent retrievers or mechanical thrombectomy are not studied for use in hepatic vessels especially in pediatric population. In our case, the stent retriever was used as rescue therapy since other methods of revascularization were exhausted. Stent retriever in stroke setting is used along with a balloon guide catheter; however, small caliber of pediatric hepatic vessels does not allow placement of large-bore balloon catheters. In our case, the stent retriever device was deployed through a 4 French catheter. This technique is easy to use, is effective, and achieves rapid recanalization as demonstrated in the index case. However, larger data are required to establish the safety and long-term patency of the treated vessels.

\section{Conflict of Interest \\ None declared.}

\section{References}

1 Stange BJ, Glanemann M, Nuessler NC, Settmacher U, Steinmüller T, Neuhaus P. Hepatic artery thrombosis after adult liver transplantation. Liver Transpl 2003;9(6):612-620

2 El-Ella KA, Al Sebayel M, Ramirez C, Hussien R. Outcome and risk factors of hepatic artery thrombosis after orthotopic liver transplantation in adults. In: Transplantation Proceedings. Transplant Proc;2001;33(5):2712-3

3 Pastacaldi S, Teixeira R, Montalto P, Rolles K, Burroughs AK. Hepatic artery thrombosis after orthotopic liver transplantation: a review of nonsurgical causes. Liver Transpl 2001;7(2):75-81

4 Del Gaudio M, Grazi GL, Ercolani G, et al. Outcome of hepatic artery reconstruction in liver transplantation with an iliac arterial interposition graft. Clin Transplant 2005;19(3):399-405

5 Gunsar F, Rolando N, Pastacaldi S, et al. Late hepatic artery thrombosis after orthotopic liver transplantation. Liver Transpl 2003;9(6):605-611

6 Abdelaziz O, Hosny K, Amin A, Emadeldin S, Uemoto S, Mostafa M. Endovascular management of early hepatic artery thrombosis after living donor liver transplantation. Transpl Int 2012;25(8):847-856 